\title{
SNF472, a novel inhibitor of vascular calcification, could be administered during hemodialysis to attain potentially therapeutic phytate levels
}

\author{
Joan Perelló ${ }^{1,2} \cdot$ M. Gómez ${ }^{3} \cdot$ M. D. Ferrer ${ }^{1,4} \cdot$ N. Y. Rodríguez ${ }^{3} \cdot$ C. Salcedo ${ }^{1} \cdot$ J. M. Buades ${ }^{5} \cdot$ M. M. Pérez ${ }^{1}$.

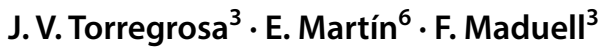

Received: 11 July 2017 / Accepted: 2 November 2017 / Published online: 19 January 2018

(c) The Author(s) 2018. This article is an open access publication

\begin{abstract}
Background Cardiovascular calcification (CVC) is a major concern in hemodialysis (HD) and the loss of endogenous modulators of calcification seems involved in the process. Phytate is an endogenous crystallization inhibitor and its low molecular mass and high water solubility make it potentially dialyzable. SNF472 (the hexasodium salt of phytate) is being developed for the treatment of calciphylaxis and CVC in HD patients. We aimed to verify if phytate is lost during dialysis, and evaluate SNF472's behaviour during dialysis.

Methods Dialyzability was assessed in vitro using online-hemodiafiltration and high-flux HD systems in blood and saline. SNF472 was infused for 20 min and quantified at different time points.

Results Phytate completely dialyzed in $1 \mathrm{~h}$ at low concentrations $(10 \mathrm{mg} / \mathrm{l})$ but not when added at 30 or $66.67 \mathrm{mg} / \mathrm{l} \mathrm{SNF} 472$. In bypass conditions, calcium was slightly chelated during SNF472 infusion but when the system was switched to dialysis mode the calcium in the bath compensated this chelation.

Conclusion Phytate dialyses with a low clearance. The administration of SNF472 as an exogenous source of phytate allows to attain supra-physiological levels required for its potential therapeutic properties. As SNF472 is infused during the whole dialysis session, the low clearance would not affect the drug's systemic exposure.
\end{abstract}

Keywords Cardiovascular calcification $\cdot$ End-stage renal disease $\cdot$ Hemodialysis $\cdot$ Phytate

\section{Introduction}

Joan Perelló

joan.perello@sanifit.com

1 Research and Development Department, Laboratoris Sanifit SL., 07121 Palma de Mallorca, Spain

2 Laboratory of Renal Lithiasis Research, IUNICS, University of the Balearic Islands, 07122 Palma, Spain

3 Nephrology and Renal Transplantation, Hospital Clínic, Barcelona, Spain

4 Departament de Biologia Fonamental i Ciències de la Salut, University of the Balearic Islands, 07122 Palma, Spain

5 Nephrology Service, Hospital Son Llàtzer, Palma de Mallorca, Spain

6 Kinrel, Madrid, Spain
Chronic kidney disease (CKD) is a serious condition associated with significant morbidity, premature mortality and decreased quality of life [1]. An improvement in renal therapy has been achieved in recent years by the addition of convective processes to the dialyzer, such as the on-line hemodiafiltration (OL-HDF) treatments [2, 3]. The overpressure applied to the dialyzer enhances the removal of plasmatic water, promoting the depuration of toxins by solvent drag. The excess of extracted intravascular water is replaced by means of a substitution flow (Qi $\mathrm{ml} / \mathrm{min}$ ), obtained from the dialysate itself. OL-HDF has demonstrated that it can deliver the most efficient removal treatment over a wide range of molecular weight (MW) uremic toxins [4] as well as improve survival [5] and quality of life.

Advanced and end-stage renal disease (ESRD) are conditions strongly associated with progressive cardiovascular calcification (CVC) [6-9]. CVC is triggered by disturbances 
in $\mathrm{Ca}$ and $\mathrm{P}$ metabolism and by the down-regulation and loss of endogenous inhibitors of calcification such as pyrophosphate [10], phytate [11], fetuin-A [12] and matrix-Gla protein [13]. A decrease in the concentrations of these endogenous inhibitors may contribute to functional impairments in CKD $[14,15]$. In fact, the development of CVC is especially enhanced in patients undergoing hemodialysis (HD), in which crystallization inhibitors seem to be lost through the dialysis system [10].

Phytate (myo-inositol hexaphosphate) is a naturallyoccurring substance found in cereals and other high-fiber foods, but it is also present in mammalian cells and tissues at concentrations in the $\mu \mathrm{M}$ range [16] and a link between phytate and health has been established, particularly with respect to calcium related diseases, such as renal stones [17-19], osteoporosis [20-22] and CVC [11, 23-25]. Phytate has been detected in human plasma with mean endogenous levels around $0.5 \mathrm{mg} / \mathrm{l}$ [26]. The low MW of phytate and its high water solubility make it potentially dialyzable and the loss of this inhibitor of crystallization during HD could additionally exacerbate the development of CVC in HD patients, as happens with pyrophosphate and bisphosphonates [10, 27]. SNF472 (an intravenous formulation of hexasodium phytate) is in active development as a novel experimental drug for the treatment of calciphylaxis and the attenuation of CVC progression in HD patients. In contrast to natural phytate, which is found in the form of its calcium-magnesium salt (also known as phytin), SNF472 consists of the hexasodium salt of phytate. The advantages of this alternative salt formulation are first its solubility (hexasodium phytate solubility in aqueous solution is $>300 \mathrm{~g} / \mathrm{l}$, while calcium-magnesium phytate is highly insoluble) and, second, that the compound can be administered without additional alterations of the calcium imbalance in HD patients. Its intended posology is intravenous infusion during dialysis, in order to obtain supra-physiological phytate plasma concentrations which would exert its therapeutic activity inhibiting CVC. Therefore, the goals of this study were to evaluate if phytate is lost through dialysis and to evaluate SNF472 behaviour through the whole dialysis circuit during the process of HD and OL-HDF.

\section{Materials and methods}

\section{Experimental design}

Whole blood was obtained from volunteer patients from the Haematology departments of the Hospital Clínic and Hospital Son Llàtzer (Mallorca, Spain) that were periodically undergoing therapeutic bleeding. A total of $1 \mathrm{~L}$ of whole blood was used in every experiment, so the blood from at least three compatible volunteers was collected per experiment forming a pool. The study was conducted in accordance with the guidelines written in the Declaration of Helsinki and all procedures involving human subjects were approved by the Ethical Committee of Clinical Investigation of the Balearic Islands. Written informed consent was obtained from all subjects.

A total of 14 different experiments were performed, 10 of them in blood and 4 in saline (Table 1). The dialysability of SNF472 was tested using three infused concentration levels (10, 30 and $66.67 \mathrm{mg} / \mathrm{l})$ in HD and OL-HDF systems. The possible interactions of SNF472 with the dialysis system were assessed in bypass conditions, in which the blood moves through the system without filtration. The experiments were performed using the FX60-Cordiax PS membrane. FX60-Cordiax is a high-flux dialyzer with the following characteristics: helixone membrane, surface $1.4 \mathrm{~m}^{2}$, ultrafiltration coefficient $47 \mathrm{ml} / \mathrm{h} / \mathrm{mmHg}, \mathrm{K}_{0}$ A Urea $1164 \mathrm{ml} /$ min, steam sterilization, B2-microglobulin sieving coefficient 0.9 , myoglobin sieving coefficient 0.5 , and albumin sieving coefficient $<0.001$. Basal clearances of cytochrome c, creatinine and urea (QB $300 \mathrm{ml} / \mathrm{min}$ ) are 96, 252 and 271, respectively. One experiment was performed using a more adsorptive BG-2.1U PMMA membrane. A longer session of a total of $4 \mathrm{~h}$ with $30 \mathrm{mg} / \mathrm{l} \mathrm{SNF} 472$ was also performed in saline in order to confirm the low clearance observed at low SNF472 doses. The possible effect of protein binding was assessed by comparing SNF472 dialysability in blood and in saline, while the possible effect of SNF472-calcium aggregates formation was assessed by comparing dialysability in the presence and absence of calcium in the dialysis bath. In these latter conditions, the absence of calcium was

Table 1 Characteristics of the experiments performed

\begin{tabular}{llllll}
\hline ID & System & Concentration & Matrix & Calcium & Membrane \\
\hline 1 & OL-HDF & $66.6 \mathrm{mg} / \mathrm{l}$ & Blood & Yes & PS \\
2 & HD & $66.6 \mathrm{mg} / \mathrm{l}$ & Blood & Yes & PS \\
3 & OL-HDF & $66.6 \mathrm{mg} / \mathrm{l}$ & Blood & Yes & PMMA \\
4 & HD & $66.6 \mathrm{mg} / \mathrm{l}$ & Blood & No & PS \\
5 & Bypass & $66.6 \mathrm{mg} / \mathrm{l}$ & Blood & Yes & PS \\
6 & OL-HDF & $30 \mathrm{mg} / 1$ & Blood & Yes & PS \\
7 & HD & $30 \mathrm{mg} / 1$ & Blood & Yes & PS \\
8 & OL-HDF & $10 \mathrm{mg} / 1$ & Blood & Yes & PS \\
9 & HD & $10 \mathrm{mg} / 1$ & Blood & Yes & PS \\
10 & Bypass & $10 \mathrm{mg} / 1$ & Blood & Yes & PS \\
11 & Bypass & $30 \mathrm{mg} / 1$ & Saline & Yes & PS \\
12 & OL-HDF & $30 \mathrm{mg} / 1$ & Saline & Yes & PS \\
13 & OL-HDF & $30 \mathrm{mg} / 1$ & Saline $(5 \mathrm{~L} ;$ & Yes & PS \\
& & $(\mathrm{bolus})$ & $4 \mathrm{~h})$ & & \\
14 & HD & $30 \mathrm{mg} / 1$ & Saline & No & PS \\
\hline
\end{tabular}

HD: hemodialysis; OL-HDF: on-line hemodiafiltration; PMMA: polymethylmethacrylate; PS: polysulfone 
compensated by a mixture of glucose, acetic acid, sodium chloride and saline in order to mimic the osmolality and conductivity of the conventional used concentrate and avoid haemolysis.

\section{In vitro dialysis sessions}

In vitro experiments were performed using FMC 4008 (Hospital Son Llàtzer) and FMC 5008 (Hospital Clínic) dialysis devices. One litre of continuously stirred saline or heparinized whole blood (heparin sodium, $1000 \mathrm{U} / \mathrm{l}$ ) kept at $37^{\circ} \mathrm{C}$ was introduced in a reservoir forming a close-loop circuit (Fig. 1). AV-Set ONLINE-Plus BVM 5008-R blood lines (FMC) and 15G needles (BBraun) were used in 5008 monitors and AV-Set SRB-R blood lines (FMC) 2008/4008 in 4008 monitors. Creatinine was added to the reservoir to attain an initial concentration of $8 \mathrm{mg} / \mathrm{dl}$. Known concentrations of SNF472 (10,30 or $66.67 \mathrm{mg} / \mathrm{l})$ were infused in the system for $20 \mathrm{~min}$ by the SNF472 infusion port by means of an infusion pump. Prior to SNF472 infusion, the system was left on HD or OL-HDF for $15 \mathrm{~min}$ in order to homogenize the initial levels of total and ionised calcium and check the performance by means of the creatinine clearance. In the 4-hour experiment, SNF472 was administered by bolus to a saline solution and the hemodialysis system ran for a total of $4 \mathrm{~h}$. In the bypass experiments (except for the experiment with $66.67 \mathrm{mg} / \mathrm{l} \mathrm{SNF} 472$ in blood), the device was also running in HD for 15 min prior to the beginning of SNF472 infusion in order to stabilize the system and increase the calcium levels at the saline reservoir, and then was switched to bypass mode just before starting SNF472 infusion.

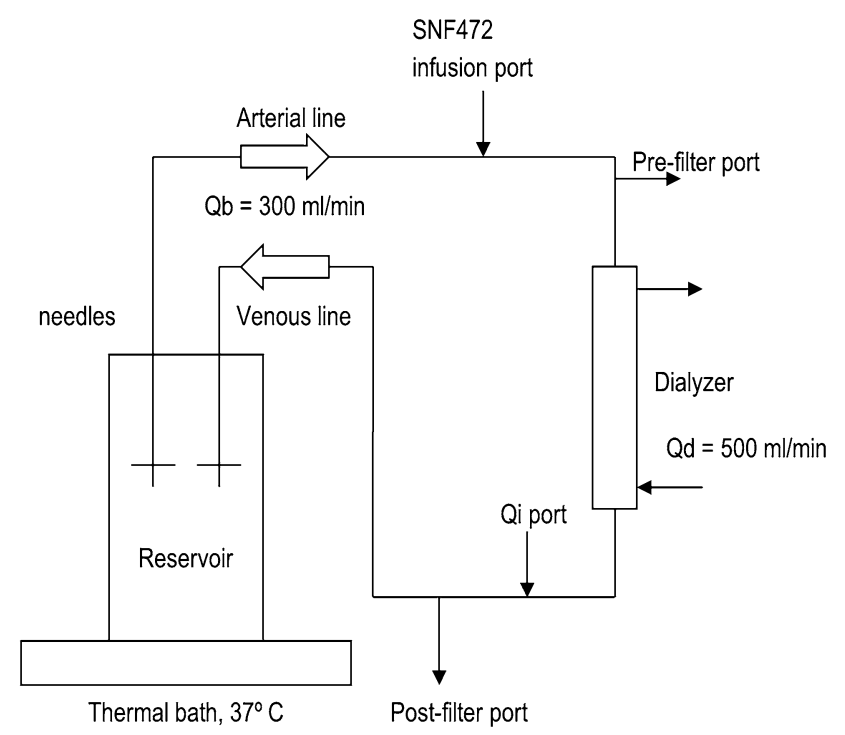

Fig. 1 Scheme of the infusion system
Blood flow, $\mathrm{Qb}$, of $300 \mathrm{ml} / \mathrm{min}$, dialysate flow, Qd, of $500 \mathrm{ml} / \mathrm{min}$ and ultrafiltrate, UF, of $96 \mathrm{ml} / \mathrm{h}$ were used in both HD and OL-HDF experiments. In addition, a substitution flow, Qi, of $80 \mathrm{ml} / \mathrm{min}$ was used in the OL-HDF experiments. In HD experiments, Qi was set to 0 whereas in bypass mode, neither Qd nor Qi was used. Calcium concentration in the ACF3A4 dialysis bath was $1.5 \mathrm{mM}$.

Blood samples were collected in $\mathrm{K}_{3}$ EDTA tubes from the pre- and post-filter ports at times $0,5,10,15,20,30$, 40, 50, $60 \mathrm{~min}$ from the beginning of the SNF472 infusion, except where stated otherwise. Samples were centrifuged at $3500 \mathrm{rpm}$ for $10^{\prime}$ and the collected serum aliquots were stored at $-80{ }^{\circ} \mathrm{C}$ until the SNF472 concentration was assayed. Additional blood samples were collected from the pre-filter port in serum collection tubes at times $-15,-7,0,7,12,17$, 22, 60 min from the beginning of the SNF472 infusion for biochemistry determinations.

\section{In vitro stability of SNF472 in human whole blood}

The in vitro metabolic stability of SNF472 in human whole blood samples was studied for $1 \mathrm{~h}$ at two SNF472 concentrations ( 2.5 and $15 \mathrm{mg} / \mathrm{l})$ and up to $4 \mathrm{~h}$ at $15 \mathrm{mg} / \mathrm{l} \mathrm{SNF} 472$. The samples were incubated at $37{ }^{\circ} \mathrm{C}$ under mild agitation and aliquots were extracted at appropriate time points. SNF472 was determined in the plasma fraction obtained after centrifugation from each incubated blood sample.

\section{SNF472 quantification by UPLC ${ }^{\circledR}$-MS}

SNF472 was quantified using the method described by Tur et al. [26]. The bioanalytical procedure involved purification and extraction by protein precipitation with TCA in the presence of EDTA. The supernatant was diluted with TEAA $50 \mathrm{mM}$ and injected into UPLC $®-M S$ system. Quantitative analysis was performed by tandem mass spectrometry in the selected ion monitoring. The molecular ion of $\mathrm{m} / \mathrm{z}$ 659 ([M.]-) was followed for quantitative purpose and was obtained after negative electrospray ionization. The compound was analysed by gradient reversed-phase chromatography using TEAA $50 \mathrm{mM} \mathrm{pH} 9$ and $\mathrm{ACN}$ as mobile phase.

\section{Creatinine, total and ionized calcium determination (HC)}

Creatinine and total calcium levels were measured by molecular absorption spectrometry. Creatinine was determined using the ADVIA 2400 analyser while total calcium was measured by CPC method using the ADVIA 1800 (Chemistry System of Siemens Healthcare Diagnostics, Chicago, IL, USA). Ionized calcium determination was performed using EPOC $®$ blood analysis card [28]. 


\section{Clearance calculations}

Creatinine clearance, $\mathrm{K}_{\mathrm{cre}}(\mathrm{ml} / \mathrm{min})$, was calculated by means of the solution of a single compartment model [29]. Assuming slight variations in volume, the expected exponential decay of the concentration can be written as:

$C(t) \approx C(0) \exp ^{-\frac{K_{\text {cret }}}{V}}$

where, $\mathrm{C}(0)(\mathrm{mg} / \mathrm{dl})$, is the initial concentration and, $\mathrm{V}$ $(\mathrm{ml})$, the system volume. The values of creatinine concentration were used to fit the $\mathrm{K}_{\text {cre }}$ parameter by means of the leastsquares method from the Gnuplot software fitting function, implementing the Levenberg-Marquardt algorithm.

Clearance of SNF472, $\mathrm{K}_{\mathrm{SNF} 472}(\mathrm{ml} / \mathrm{min})$, was calculated by two different strategies. The first one involved the same exponential fitting method for creatinine, using SNF472 prefilter levels. The second one was performed by means of calculating Eq. (2) [30] at each sampled time:

$K_{S N F 472}=(100-H t) Q_{b}\left(\frac{C_{i}-C_{o}}{C_{i}}\right)+U F\left(\frac{C_{o}}{C_{i}}\right)$

where $H t$ is the \% of haematocrit, and $C_{i}$ and $C_{o}$ are the concentrations at the pre-and post-filter ports, respectively.

As we measured $C_{o}>C_{i}$ in several time intervals for SNF472, Eq. 2 was not useful to obtain realistic clearance values. The presented results are obtained from the exponential fitting.

\section{Results}

SNF472 increased in blood while infused, reached a plateau and remained nearly constant when added at concentrations of 30 and $66.67 \mathrm{mg} / \mathrm{l}$ (Fig. 2A-D). The use of a polymethylmethacrylate (PMMA) membrane instead of a polysulfone (PS) membrane did not affect the dialysability of SNF472. There was no apparent loss of SNF472 when the system ran in bypass mode. However, when SNF472 was added at $10 \mathrm{mg} / \mathrm{l}$ its levels in blood increased up to $8 \mathrm{mg} / \mathrm{l}$ during the infusion but then dropped with estimated values of $\mathrm{K}_{\mathrm{SNF} 472}$ of $36 \pm 3$ and $17 \pm 4 \mathrm{ml} / \mathrm{min}$ for OL-HDF and HD, respectively (Fig. 2E-F; Table 2). A longer experiment was performed with SNF472 at a final concentration of $30 \mathrm{mg} / \mathrm{l}$ subjected to dialysis for a total of $4 \mathrm{~h}$ (Fig. 2G). The results of the experiment confirmed that SNF472 dialyzed also at $30 \mathrm{mg} / \mathrm{l}$ but with a clearance so low that it was not detected in the 1-hour experiments when the compound was at or above $30 \mathrm{mg} / \mathrm{l}$. An in vitro stability test was performed in human whole blood in order to discard SNF472 degradation during the hour of incubation. As observed in Fig. 2H, SNF472 is stable for up to
$4 \mathrm{~h}$ in blood at $37^{\circ} \mathrm{C}$, at concentrations between 2.5 and $15 \mathrm{mg} / \mathrm{l}$.

Creatinine dialyzed with $\mathrm{K}_{\text {cre }}$ values of $204 \pm 23$ and $161 \pm 17 \mathrm{ml} / \mathrm{min}$ for OL-HDF and HD, respectively (Fig. 3). Ionized calcium levels were low in bypass mode ( $25 \%$ of total calcium) but this was resolved when switching the system to dialysis mode, arriving to ionized calcium levels around $60-70 \%$ of total calcium.

In order to check if the lack of dialysability observed at high concentrations was due to interactions with blood proteins, the assays were performed in saline with $30 \mathrm{mg} / \mathrm{l}$ SNF472. As seen in Fig. 4A, B, SNF472 reached maximum plateau levels after infusion and these were maintained up until the end of the 60-min period. Creatinine correctly dialyzed in these conditions (Fig. 4C). In the bypass experiments (except for the experiment with $66.67 \mathrm{mg} / \mathrm{l} \mathrm{SNF} 472$ in blood), the device was running in HD for 15 min prior to the beginning of SNF472 infusion in order to stabilize the system and increase the calcium levels at the saline reservoir, and then was switched to bypass mode just before starting SNF472 infusion. In these conditions a very slight chelation of calcium by SNF472 was observed (Fig. 4D).

Finally, the experiments were performed using a calcium-free dialysate in order to study the possible effect of SNF472-calcium aggregates formation. The system was previously stabilized for $15 \mathrm{~min}$ in $\mathrm{HD}$, and then this was changed to a calcium-free concentrate. SNF472 levels rose in blood for the $20 \mathrm{~min}$ of infusion while total and ionized calcium levels dropped (Fig. 5A, D). In the absence of calcium, SNF472 dialyzed in HD with a $\mathrm{K}_{\mathrm{SFN} 472}$ of $115 \pm 6 \mathrm{ml} / \mathrm{min}$ for the $66.67 \mathrm{mg} / \mathrm{l}$ tested concentration and was undetectable after $50 \mathrm{~min}$ of study. A similar behaviour was observed when the assay was performed in saline in $\mathrm{HD}$ with $30 \mathrm{mg} / \mathrm{l}$ with a $\mathrm{K}_{\mathrm{SFN} 472}$ of $80 \pm 13 \mathrm{ml} /$ $\min$ (Fig. 5B, D).

\section{Discussion}

Patients with CKD exhibit more CVC than age-matched healthy individuals, and patients receiving HD therapy are reported to have calcification scores over fivefold higher than matched individuals with established coronary artery disease but normal kidney function [31]. The presence of CVC is also a strong predictor of future cardiovascular (CV) events, $\mathrm{CV}$ death and all-cause mortality $[32,33]$, but there are currently no approved therapies indicated for the treatment of CVC. A number of potential therapies target the calcification process, but these are currently experimental and there are few controlled studies on which to base therapeutic decisions. There is certain evidence that treatments designed to control parathyroid hormone (PTH), Ca and P levels in 

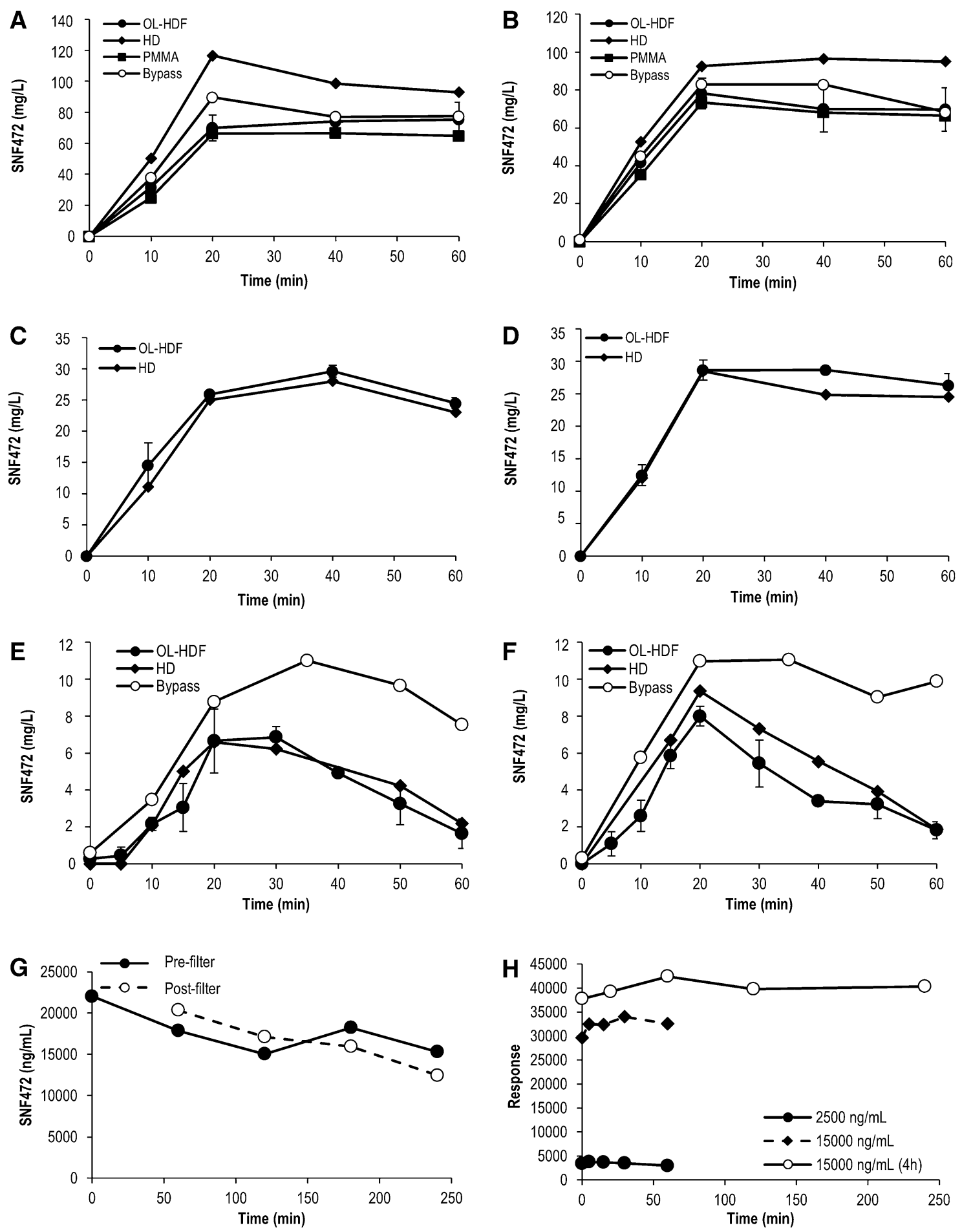

Fig. 2 In vitro dialysability and stability of SNF472 under different experimental conditions. (A) $66.67 \mathrm{mg} / 1 \mathrm{SNF} 472$, pre-filter sampling;

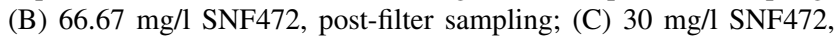
pre-filter sampling; (D) $30 \mathrm{mg} / \mathrm{l} \mathrm{SNF472,} \mathrm{post-filter} \mathrm{sampling;} \mathrm{(E)}$ $10 \mathrm{mg} / \mathrm{l} \mathrm{SNF} 472$, pre-filter sampling; (F) $10 \mathrm{mg} / \mathrm{l} \mathrm{SNF472,} \mathrm{post-}$ filter sampling; (G) $30 \mathrm{mg} / \mathrm{l} \mathrm{SNF} 472$ in saline with OL-HDF; (H) in

vitro stability of 2.5 and $15 \mathrm{mg} / \mathrm{l} \mathrm{SNF} 472$ in human blood at $37{ }^{\circ} \mathrm{C}$. (A-F) SNF472 was infused at different concentrations for $20 \mathrm{~min}$ in 11 blood. OL-HDF experiments performed in triplicate, mean \pm SEM is represented HD and bypass experiments performed in single experiments. OL-HDF: online-hemodiafiltration; HD: hemodialysis; PMMA: polymethylmethacrylate membrane 
Table 2 Clearance values for creatinine and SNF472 infused in blood and saline

\begin{tabular}{|c|c|c|}
\hline Experiment & $\begin{array}{l}\text { SNF472 clearance } \\
(\mathrm{ml} / \mathrm{min})\end{array}$ & $\begin{array}{l}\text { Creatinine } \\
\text { clearance }(\mathrm{ml} / \\
\text { min) }\end{array}$ \\
\hline OL-HDF - Blood ${ }^{1}$ & $36 \pm 3$ & $204 \pm 23$ \\
\hline HD - Blood ${ }^{1}$ & $17 \pm 4$ & $161 \pm 17$ \\
\hline OL-HDF - Saline ${ }^{3}$ & $7 \pm 2$ & $321 \pm 35$ \\
\hline HD - no calcium - Blood ${ }^{2}$ & $115 \pm 6$ & $171 \pm 25$ \\
\hline HD - no calcium - Saline ${ }^{3}$ & $80 \pm 13$ & $238 \pm 7$ \\
\hline
\end{tabular}

Clearance of SNF472 was calculated by the exponential fitting method for creatinine, using SNF472 pre-filter levels. Results represent fitted parameter mean values \pm asymptotic estimated error

${ }^{1} 10 \mathrm{mg} / 1 \mathrm{SNF} 472$

${ }^{2} 66.67 \mathrm{mg} / \mathrm{l} \mathrm{SNF} 472$

${ }^{3} 30 \mathrm{mg} / 1 \mathrm{SNF} 472$

patients with advanced CKD such as calcimimetics and phosphate binders may attenuate calcification progression in HD patients with secondary hyperparathyroidism [34-38].

The mechanisms by which soft tissue calcification in HD patients is triggered are not fully understood but disturbances in $\mathrm{Ca}$ and $\mathrm{P}$ metabolism and the down-regulation of endogenous inhibitors of calcification at early stages of the disease and its loss during dialysis seem to be involved [14, 15], together with the transdifferentiation of vascular smooth muscle cells (VSMC) towards an osteoblast-like phenotype $[39,40]$. The development and acceleration of CVC is especially enhanced in patients undergoing dialysis, in which pyrophosphate seems to be lost through the dialysis system $[10,41]$. Phytate is a naturally-occurring substance found in cereals but also present in mammalian cells and tissues at concentrations in the $\mu \mathrm{M}$ range [16] and in human plasma at concentrations below $0.5 \mathrm{mg} / \mathrm{l}$ [26]. Phytate is a potent endogenous inhibitor of hydroxyapatite (HAP) crystallization that acts by interfering the deposition of new calcium and phosphorus ions on the growing HAP crystals [42]. Animal studies with rat models of calcification have shown a promising effect of phytate on the inhibition of CVC in vivo [23-25]. However, the low MW of phytate and its high water solubility make it potentially dialyzable and the loss of this inhibitor during HD could additionally exacerbate the development of CVC. A recent publication hypothesized that the dietary intake of phytate could attenuate the development of age-related CVC [11], even at the early stages of CKD [43], and the accelerated CVC seen in HD patients could be partially explained by the loss of phytate and be counteracted by supra-physiological phytate plasma concentrations that cannot be achieved by the oral route due to the limited gastro-intestinal absorption. SNF472 is a novel experimental drug with phytate as its active principle which is currently in development for the treatment of calciphylaxis and the attenuation of CVC progression in HD patients. The intended posology of SNF472 is intravenous infusion during dialysis, in order to obtain supra-physiological phytate plasma concentrations which would produce its therapeutic activity inhibiting CVC.

In the current study, in an in vitro setting of HD we demonstrated that phytate dialyzes from blood with a low clearance and this dialyzation becomes especially relevant when the compound is present at low concentrations (around or below $10 \mathrm{mg} / \mathrm{l}$ ). SNF472 was infused to the blood for 20 min until reaching the desired final concentrations $(10$, 30 and $66.67 \mathrm{mg} / \mathrm{l}$ ) and then dialysability of the compound was followed for 40 additional min. Once the desired levels were attained, no significant loss was observed when the compound was added at 30 and $66.67 \mathrm{mg} / \mathrm{l}$ but significant dialysability was observed at $10 \mathrm{mg} / \mathrm{l}$ with $\mathrm{K}_{\mathrm{SNF} 472}$ values of $36 \pm 3$ and $17 \pm 4 \mathrm{ml} / \mathrm{min}$ for OL-HDF and HD, respectively. This higher clearance observed in the OL-HDF system is comprehensible as this system applies a high convention at the filter, extracting the plasma water at a rate of around $80 \mathrm{ml} / \mathrm{min}$ which could enhance the depuration of the studied solute. The difference in dialysability found in the different SNF472 concentrations tested is explained by the low clearance of the compound, as the extension of the dialysis session to $4 \mathrm{~h}$ confirmed this low clearance also when SNF472 was present at $30 \mathrm{mg} / \mathrm{l}$. In order to discard an effect of SNF472 degradation during the time of dialysis, an in vitro stability assay was performed and the results obtained confirmed that the observed loss of SNF472 was in fact due to dialyzation rather than to degradation. Although relevant dialysability of SNF472 was observed at $10 \mathrm{mg} / \mathrm{l}$, it must be noted that during the infusion period the final desired levels were nearly attained and the clearance of the compound is almost 10 times lower than that of creatinine. This behaviour is similar to previous observations in other polyphosphate compounds such as pyrophosphate and bisphosphonates. The quantification of pyrophosphate levels in blood of HD patients both before and after HD treatment revealed a significant $32 \%$ decrease [10] in this substance content. Similarly, the measurement of pamidronate levels after a 2-h dialysis session revealed a $32 \%$ loss of this substance through the dialysis membrane with a clearance of $69.3 \mathrm{ml} /$ min [27] whereas for clodronate [44] the reported values of clearance were $87.8 \pm 16.2 \mathrm{ml} / \mathrm{min}$ in HD patients, both of them lower than that found in urea or creatinine but higher than the value we report for SNF472 (17 ml/min in HD). These results evidence that phytate is lost during dialysis with a low clearance, but considering the very low endogenous levels of phytate (around $0.5 \mathrm{mg} / \mathrm{l}$ ) this low clearance can be enough to deplete circulating phytate in HD patients, thus exposing these patients to accelerated development of CVC. SNF472 is a novel approach to obtain sustained high phytate plasma levels in these patients. 

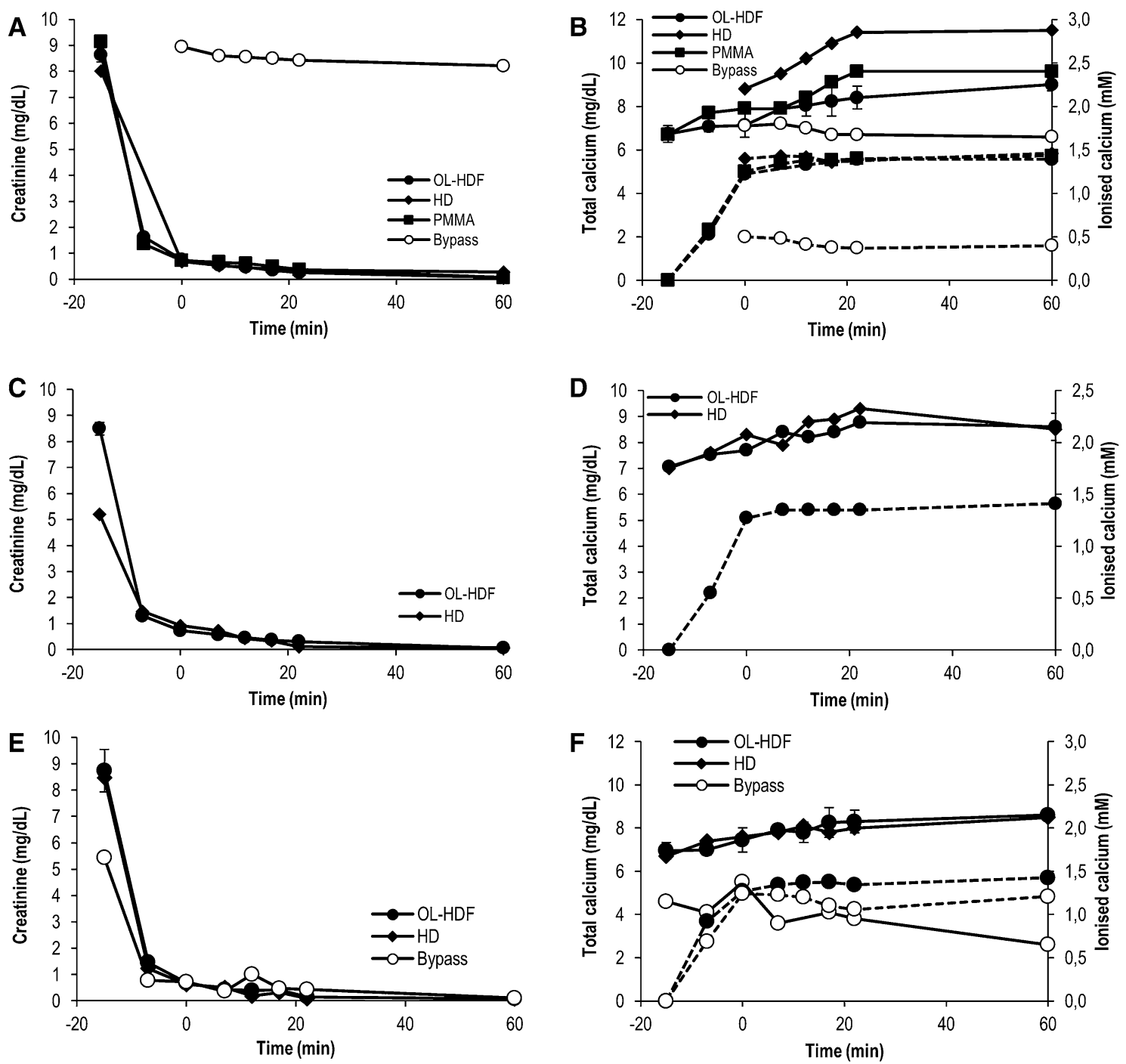

Fig. 3 Creatinine clearance and SNF472 effect on calcium levels in in vitro dialysis systems. SNF472 was infused at different concentrations for $20 \mathrm{~min}$ in 11 blood. (A, B) $66.67 \mathrm{mg} / \mathrm{l} \mathrm{SNF} 472$; (C, D) $30 \mathrm{mg} / \mathrm{l} \mathrm{SNF} 472$; (E, F) $10 \mathrm{mg} / \mathrm{l} \mathrm{SNF} 472$. In (B, D and F) solid lines represent total calcium while dashed lines represent ionized calcium.

Phytate has already been shown to bind to proteins [16], especially on the cell membrane of erythrocytes, without entering into the intracellular space due to the presence of high negative charge $[45,46]$. Therefore, SNF472 in blood could be found bound to cell membrane or plasma soluble proteins and this would make its dialyzation difficult. The nature of the circulating proteins which bind phytate is not known, but the high negative charge of the compound points to unspecific charge-charge interactions, possibly through calcium ions forming phytate-calcium-protein complexes. However, the same results were obtained when experiments were performed in blood and in saline, so the possibility of protein binding being the main or only cause for the low

OL-HDF experiments performed in triplicate, mean \pm SEM is represented. HD and bypass experiments performed in single experiments. OL-HDF: online-hemodiafiltration; HD: hemodialysis; PMMA: polymethylmethacrylate membrane

dialysability of the drug was discarded and other mechanisms to retain SNF472 are likely involved.

The presence of six negative charges on the surface of the molecule also provides SNF472 with the capability to chelate divalent cations such as calcium. The formation of colloidal SNF472-calcium complexes with a characteristic size and charge could avoid their passage through the dialysis membrane pores. When experiments were performed without calcium in the dialysate, dialysability of SNF472 was evidenced after finishing the infusion, even at the $66.67 \mathrm{mg} / \mathrm{l}$ concentration, with $\mathrm{K}_{\mathrm{SNF} 472}$ of $115 \pm 6$ and $80 \pm 13 \mathrm{ml} / \mathrm{min}$ in blood and saline, respectively. These results taken altogether point to the formation of SNF472-calcium complexes that would be multi-charged (both positively and negatively) 

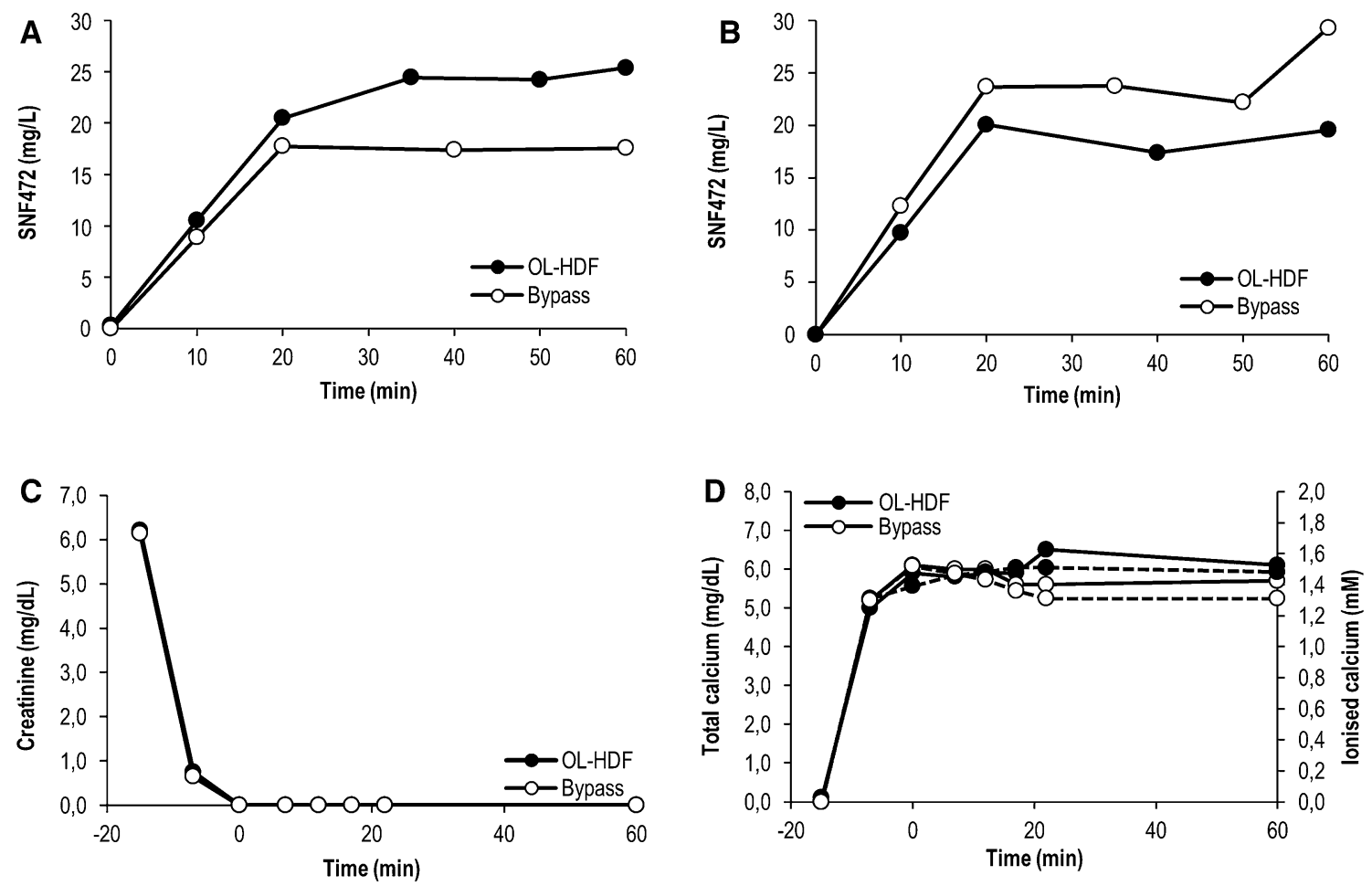

Fig. 4 In vitro dialysability of $30 \mathrm{mg} / \mathrm{l} \mathrm{SNF} 472$ under different experimental conditions in saline samples. SNF472 was infused at $30 \mathrm{mg} / \mathrm{l}$ for $20 \mathrm{~min}$ in 11 saline. (A) Pre-filter sampling; (B) Post-filter sam-

pling; (C) Creatinine clearance; (D) Total (solid lines) and ionized (dashed lines) calcium levels. OL-HDF: online-hemodiafiltration
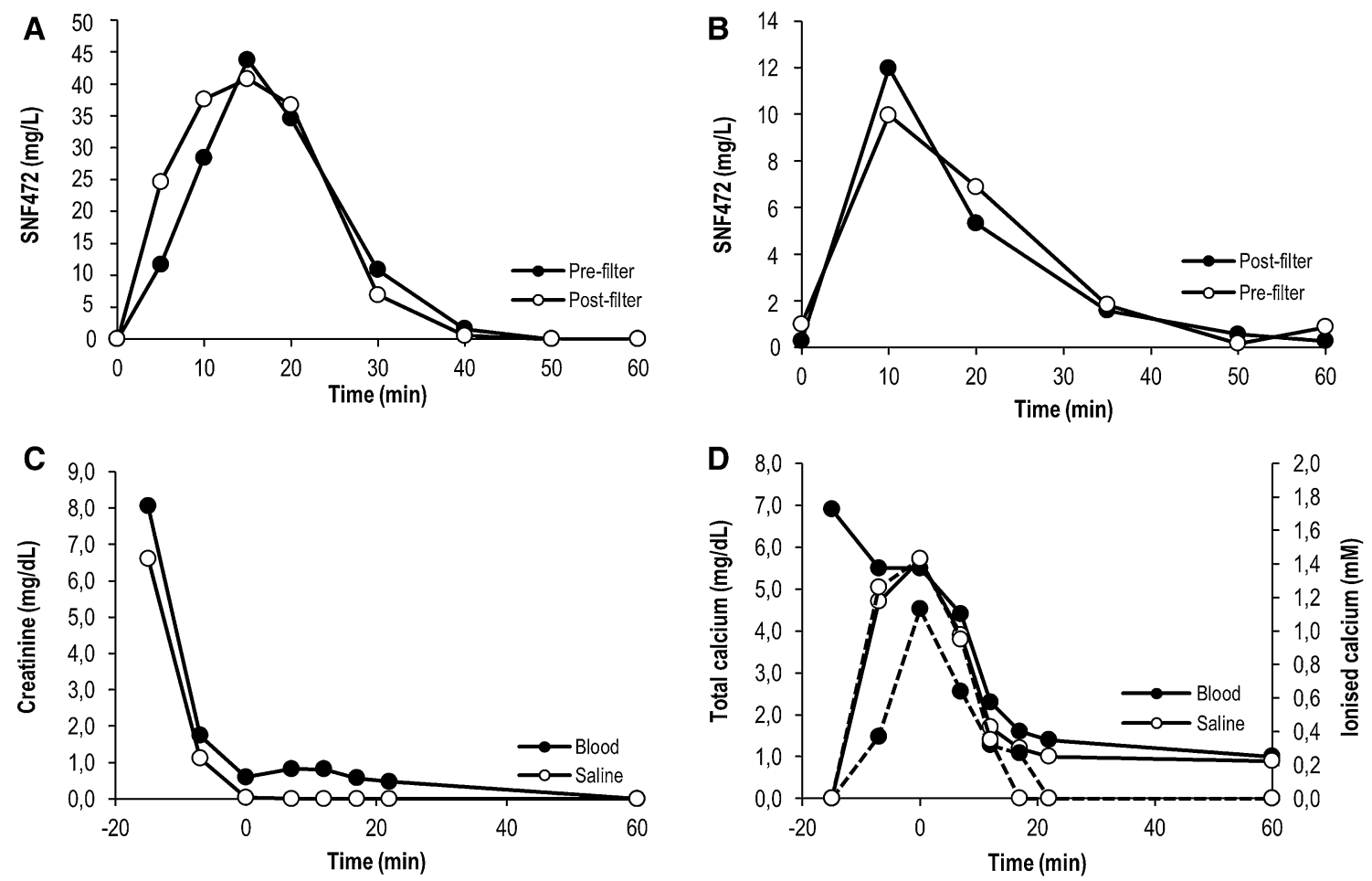

Fig. 5 In vitro SNF472 dialysability in blood and saline in the absence of calcium in the dialysis bath. SNF472 was infused for 20 min at (A) $66.67 \mathrm{mg} / \mathrm{l}$ in 11 blood or (B) $30 \mathrm{mg} / \mathrm{l}$ in 11 saline; (C) Creatinine clearance; (D) Total (solid lines) and ionized (dashed lines) calcium levels 
and with a size enough to render difficult their dialyzation. Although the formation of these complexes implies a slight chelation of calcium by SNF472, no significant decrease in ionized calcium levels was observed, which should be attributed to the compensating effect of the dialysis bath in the calcium concentration. The small clearance of SNF472 as well as the slight calcium chelation could be explained by assuming the formation and disassociation of the calcium aggregates in a dynamical regime, which leads to a low dialysability of the compound due to its size and charge. However, in the calcium-free experiments, levels of SNF472 increase to a lower than expected level, and the maximum peak is reached before the total infusion of the compound. The amount of calcium in the first minutes of this experiment leads to a dynamical formation and disassociation of calcium aggregates while there is enough calcium at the reservoir. When the calcium depletion of the reservoir reaches a threshold level, aggregates cannot be reassembled, leading to free SNF472 to be dialyzed, even while the compound is still infused in the system. However, as a rich-calcium dialysate was formerly used both in HD and OL-HDF treatments, slight chelation of calcium levels of the dialysis bath does not represent a significant cation depletion. Therefore, these results evidence that in addition to protein binding, SNF472 binds to calcium to form colloidal aggregates that cannot cross the dialysis membrane.

In conclusion, SNF472 dialyses out with a low clearance, evidencing that the endogenous crystallization inhibitor phytate is lost during dialysis. The low dialysability compared to other structurally similar molecules seems mainly due to the formation of complexes with calcium. The intravenous administration of SNF472 during the dialysis session could provide the means to increase phytate levels to supra-physiological values with the potential to slow down the progression of CVC in ESRD patients. When SNF472 is administered through infusion, its levels increase in blood during the infusion period and dialysis does not prevent from attaining potentially therapeutic levels, as the levels reached at concentrations of $10 \mathrm{mg} / \mathrm{l}$ are the ones that showed efficacy in the in vitro and in vivo efficacy tests [47] as well as in pharmacodynamic measurements performed in Phase 1 clinical trials with SNF472 [48]. The chelating effects of SNF472 on calcium are compensated by the calcium in the dialysis bath, so hypocalcaemia in the dialysis setting is unlikely.

Acknowledgements This study has been supported by REDINREN RD012/0021 and RETOS COLABORACIÓN RTC201424601 ISCIII (Ministerio de Economía y Competitividad. Government of Spain) grants.

\section{Compliance with Ethical Standards}

Conflict of interest MF, CS, MMP and JP are employees or receive honoraria from Laboratoris Sanifit SL. JP is shareholder at Laboratoris Sanifit SL. The remaining authors do not declare any competing financial interests. SNF472, a novel inhibitor of vascular calcification, could be administered during hemodialysis to attain potentially therapeutic phytate levels.

Ethical standards The study was conducted in accordance with the guidelines written in the Declaration of Helsinki and all procedures involving human subjects were approved by the Ethical Committee of Clinical Investigation of the Balearic Islands.

Open Access This article is distributed under the terms of the Creative Commons Attribution 4.0 International License (http://creativecommons.org/licenses/by/4.0/), which permits unrestricted use, distribution, and reproduction in any medium, provided you give appropriate credit to the original author(s) and the source, provide a link to the Creative Commons license, and indicate if changes were made.

\section{References}

1. Zoccali C, Kramer A, Jager KJ (2010) Chronic kidney disease and end-stage renal disease - A review produced to contribute to the report "the status of health in the European union: Towards a healthier Europe". Nephrol Dial Transplant Plus 3:213-224

2. Tattersall JE, Ward RA (2013) Online haemodiafiltration: definition, dose quantification and safety revisited. Nephrol Dial Transplant 28:542-550

3. Bourguignon C, Chenine L, Bargnoux AS, Leray-Moragues H, Canaud B et al (2016) Hemodiafiltration improves free light chain removal and normalizes kappa/lambda ratio in hemodialysis patients. J Nephrol 29:251-257

4. Maduell F, del Pozo C, Garcia H, Sanchez L, Hdez-Jaras J et al (1999) Change from conventional haemodiafiltration to on-line haemodiafiltration. Nephrol Dial Transplant 14:1202-1207

5. Maduell F, Moreso F, Pons M, Ramos R, Mora-Macia J et al (2013) High-efficiency postdilution online hemodiafiltration reduces all-cause mortality in hemodialysis patients. J Am Soc Nephrol 24:487-497

6. Cozzolino M, Brancaccio D, Gallieni M, Slatopolsky E (2005) Pathogenesis of vascular calcification in chronic kidney disease. Kidney Int 68:429-436

7. Adragao T, Pires A, Lucas C, Birne R, Magalhaes L et al (2004) A simple vascular calcification score predicts cardiovascular risk in haemodialysis patients. Nephrol Dial Transplant 19:1480-1488

8. Jean G, Bresson E, Terrat JC, Vanel T, Hurot JM et al (2009) Peripheral vascular calcification in long-haemodialysis patients: associated factors and survival consequences. Nephrol Dial Transplant 24:948-955

9. Russo D, Palmiero G, De Blasio AP, Balletta MM, Andreucci VE (2004) Coronary artery calcification in patients with CRF not undergoing dialysis. Am J Kidney Dis 44:1024-1030

10. Lomashvili KA, Khawandi W, O’Neill WC (2005) Reduced plasma pyrophosphate levels in hemodialysis patients. J Am Soc Nephrol 16:2495-2500

11. Joubert P, Ketteler M, Salcedo C, Perello J (2016) Hypothesis: Phytate is an important unrecognised nutrient and potential intravenous drug for preventing vascular calcification. Med Hypotheses 94:89-92 
12. Schinke T, Amendt C, Trindl A, Poschke O, Muller-Esterl W et al (1996) The serum protein alpha2-HS glycoprotein/fetuin inhibits apatite formation in vitro and in mineralizing calvaria cells. A possible role in mineralization and calcium homeostasis. J Biol Chem 271:20789-20796

13. Luo G, Ducy P, McKee MD, Pinero GJ, Loyer E et al (1997) Spontaneous calcification of arteries and cartilage in mice lacking matrix GLA protein. Nature 386:78-81

14. Schlieper G, Westenfeld R, Brandenburg V, Ketteler M (2007) Inhibitors of calcification in blood and urine. Semin Dial 20:113-121

15. Ketteler M, Bongartz $P$, Westenfeld R, Wildberger JE, Mahnken AH et al (2003) Association of low fetuin-A (AHSG) concentrations in serum with cardiovascular mortality in patients on dialysis: a cross-sectional study. Lancet 361:827-833

16. Shears SB (2001) Assessing the omnipotence of inositol hexakisphosphate. Cell Signal 13:151-158

17. Grases F, March JG, Prieto RM, Simonet BM, Costa-Bauza A et al (2000) Urinary phytate in calcium oxalate stone formers and healthy people-dietary effects on phytate excretion. Scand J Urol Nephrol 34:162-164

18. Curhan GC, Willet WC, Knight EL, Stampfer MJ (2004) Dietary factors and the risk of incident kidney stones in younger women: Nurses! Health Study II. Arch Intern Med 164:885-891

19. Conte A, Pizá P, Garcia-Raja A, Grases F, Costa-Bauza A et al (1999) Urinary lithogen risk test: usefulness in the evaluation of renal lithiasis treatment using crystallization inhibitors (citrate and phytate). Arch Esp Urol 52:305-310

20. Grases F, Sanchis P, Prieto RM, Perello J, Lopez-Gonzalez AA (2010) Effect of tetracalcium dimagnesium phytate on bone characteristics in ovariectomized rats. J Med Food 13:1301-1306

21. Lopez-Gonzalez AA, Grases F, Roca P, Mari B, Vicente-Herrero MT et al (2008) Phytate (myo-inositol hexaphosphate) and risk factors for osteoporosis. J Med Food 11:747-752

22. Lopez-Gonzalez AA, Grases F, Perello J, Tur F, Costa-Bauza A et al (2010) Phytate levels and bone parameters: a retrospective pilot clinical trial. Front Biosci (Elite Ed) 2:1093-1098

23. Grases F, Sanchis P, Perello J, Isern B, Prieto RM et al (2006) Phytate (Myo-inositol hexakisphosphate) inhibits cardiovascular calcifications in rats. Front Biosci 11:136-142

24. Grases F, Sanchis P, Perello J, Isern B, Prieto RM et al (2007) Effect of crystallization inhibitors on vascular calcifications induced by vitamin D: a pilot study in Sprague-Dawley rats. Circ J 71:1152-1156

25. Van den Berg CJ, Hill LF, Stanbury SW (1972) Inositol phosphates and phytic acid as inhibitors of biological calcification in the rat. Clin Sci 43:377-383

26. Tur F, Tur E, Lentheric I, Mendoza P, Encabo M et al (2013) Validation of an LC-MS bioanalytical method for quantification of phytate levels in rat, dog and human plasma. J Chromatogr B Analyt Technol Biomed Life Sci 928:146-154

27. Buttazzoni M, Rosa Diez GJ, Jager V, Crucelegui MS, Algranati SL et al (2006) Elimination and clearance of pamidronate by haemodialysis. Nephrology (Carlton) 11:197-200

28. Nernst W (1889) Über Die Elektromotorische Wirksamkeit Der Jonen. Zeitschrift Fur Physikalische Chemie 129-181

29. Waniewski J (2006) Mathematical modeling of fluid and solute transport in hemodialysis and peritoneal dialysis. J Membr Sci 274:24-37

30. Ward RA, Greene T, Hartmann B, Samtleben W (2006) Resistance to intercompartmental mass transfer limits beta2-microglobulin removal by post-dilution hemodiafiltration. Kidney Int 69:1431-1437

31. Moe SM, Chen NX (2004) Pathophysiology of vascular calcification in chronic kidney disease. Circ Res 95:560-567

32. Raggi P, Callister TQ, Shaw LJ (2004) Progression of coronary artery calcium and risk of first myocardial infarction in patients receiving cholesterol-lowering therapy. Arterioscler Thromb Vasc Biol 24:1272-1277

33. Detrano R, Guerci AD, Carr JJ, Bild DE, Burke G et al (2008) Coronary calcium as a predictor of coronary events in four racial or ethnic groups. N Engl J Med 358:1336-1345

34. Block GA, Spiegel DM, Ehrlich J, Mehta R, Lindbergh J et al (2005) Effects of sevelamer and calcium on coronary artery calcification in patients new to hemodialysis. Kidney Int 68:1815-1824

35. Block GA, Raggi P, Bellasi A, Kooienga L, Spiegel DM (2007) Mortality effect of coronary calcification and phosphate binder choice in incident hemodialysis patients. Kidney Int 71:438-441

36. Raggi P, Chertow GM, Torres PU, Csiky B, Naso A et al (2011) The ADVANCE study: a randomized study to evaluate the effects of cinacalcet plus low-dose vitamin $\mathrm{D}$ on vascular calcification in patients on hemodialysis. Nephrol Dial Transplant 26:1327-1339

37. Chertow GM, Burke SK, Raggi P (2002) Sevelamer attenuates the progression of coronary and aortic calcification in hemodialysis patients. Kidney Int 62:245-252

38. Russo D, Bellasi A, Pota A, Russo L, Di Iorio B (2015) Effects of phosphorus-restricted diet and phosphate-binding therapy on outcomes in patients with chronic kidney disease. J Nephrol 28:73-80

39. Neven E, Persy V, Dauwe S, De Schutter T, De Broe ME et al (2010) Chondrocyte rather than osteoblast conversion of vascular cells underlies medial calcification in uremic rats. Arterioscler Thromb Vasc Biol 30:1741-1750

40. Neven E, Dauwe S, De Broe ME, D'Haese PC, Persy V (2007) Endochondral bone formation is involved in media calcification in rats and in men. Kidney Int 72:574-581

41. Rezg R, Barreto FC, Barreto DV, Liabeuf S, Drueke TB et al (2011) Inhibitors of vascular calcification as potential therapeutic targets. J Nephrol 24:416-427

42. Grases F, Llobera A (1996) Determination of phytic acid in urine by ICP atomic emission spectrometry. Anal Lett 29:1193-1199

43. Sanchis P, Buades JM, Berga F, Gelabert MM, Molina M et al (2016) Protective Effect of Myo-Inositol Hexaphosphate (Phytate) on Abdominal Aortic Calcification in Patients With Chronic Kidney Disease. J Ren Nutr 26:226-236

44. Ala-Houhala I, Saha H, Liukko-Sipi S, Ylitalo P, Pasternack A (1999) Pharmacokinetics of clodronate in haemodialysis patients. Nephrol Dial Transplant 14:699-705

45. Vincent SP, Lehn JM, Lazarte J, Nicolau C (2002) Transport of the highly charged myo-inositol hexakisphosphate molecule across the red blood cell membrane: a phase transfer and biological study. Bioorg Med Chem 10:2825-2834

46. Schlemmer U, Frolich W, Prieto RM, Grases F (2009) Phytate in foods and significance for humans: food sources, intake, processing, bioavailability, protective role and analysis. Mol Nutr Food Res 53(Suppl 2):S330-S375

47. Perelló J, Salcedo C, Neven E, Behets GJ, Joubert PH et al (2015) SNF472 Inhibits Cardiovascular Calcification in Uremic Rats (Poster). J Am Soc Nephrol 26:1034A

48. Perelló J, Salcedo C, Joubert PH, Canals AZ, Ferrer MD (2015) First-time-in-human phase 1 clinical trial in healthy volunteers with SNF472, a novel inhibitor of vascular calcification (Poster). Nephrol Dial Transplant 30:iii592 